\section{Brazilian Journal \\ of Chemical \\ Engineering}

ISSN 0104-6632

Printed in Brazil

www.scielo.br/bjce

Vol. 35, No. 01, pp. 229 - 236, January - March, 2018

(cc) BY

dx.doi.org/10.1590/0104-6632.20180351s20160171

\title{
FRACTIONATION OF APIS MELLIFERA VENOM BY MEANS OF ULTRAFILTRATION: REMOVAL OF PHOSPHOLIPASE $\mathrm{A}_{2}$
}

\author{
Júlio César Moreira de Brito ${ }^{1,2}$, Esther Margarida Alves Ferreira Bastos ${ }^{1}$, \\ Luiz Guilherme Dias Heneine ${ }^{1}$ and Kátia Cecília de Souza Figueiredo ${ }^{2 *}$ \\ ${ }^{1}$ Fundação Ezequiel Dias, Diretoria de Pesquisa e Desenvolvimento. Rua Conde Pereira Carneiro, 80, Gameleira. \\ Zip code 305100-010, Belo Horizonte, Minas Gerais, Brazil. \\ ${ }^{2}$ Universidade Federal de Minas Gerais, Escola de Engenharia, Departamento de Engenharia Química, Bloco 2, Sala 5206. \\ Avenida Presidente Antônio Carlos, 6627. Zip code 31270-901, Belo Horizonte, Minas Gerais, Brazil.
}

(Submitted: March 13, 2016; Revised: September 5, 2016; Accepted: October 5, 2016)

\begin{abstract}
The fractionation of apitoxin (bee venom) by means of a commercial $10 \mathrm{kDa}$ ultrafiltration membrane was investigated aiming at the removal of phospholipase $\mathrm{A}_{2}$, the main allergenic substance. The feed content was varied from 1 to $50 \mathrm{~g}$ apitoxin/L, in deionized water, and caused changes in membrane flux and rejection, due to concentration polarization. The increase in pressure difference and stirring rate improved the flux through the membrane. The best result was achieved for $1 \mathrm{~g}$ apitoxin/L in feed stream, with a pressure difference of $220 \mathrm{kPa}$, and $750 \mathrm{rpm}$, with a permeate flux of $103 \mathrm{~kg} / \mathrm{m}^{2} \mathrm{~h}$. The use of ultrafiltration was efficient to improve the permeate safety since biological tests revealed that the remaining enzyme lost its ability to catalyze the hydrolysis of phospholipids.
\end{abstract}

Keywords: apitoxin; melittin; membrane; phospholipase $\mathrm{A}_{2}$; ultrafiltration.

\section{INTRODUCTION}

Rheumatoid arthritis is a chronic inflammatory and autoimmune disease that affects the joints, causing pain, deformations and disability. As an alternative, the venom of Apis mellifera (apitoxin) has shown positive results when used to treat rheumatoid arthritis (Dong et al., 2007). Apitoxin contains a variety of compounds such as melittin $(2,840 \mathrm{Da})$, apamin $(2,036 \mathrm{Da})$, minimide $(6,000 \mathrm{Da})$, adolapin $(11,500$ Da), MCD peptide (2,586 Da), phospholipase $A_{2}(19,000$ $\mathrm{Da})$, hyaluronidase $(38,000 \mathrm{Da})$, phosphomonoesterases $(55,000 \mathrm{Da})$, and glicosidase $(170,000 \mathrm{Da})$. Melittin is the major component of apitoxin, around $50 \%$ in weight.

The bee venom fraction containing melittin is well known as an anti-inflammatory vehicle (Merlo et al., 2011). On the other hand, studies in patients allergic to bee venom demonstrated that phospholipase $\mathrm{A}_{2}$, phosphomonoesterase and hyaluronidase are the major allergens present in apitoxin (Müller et al., 2012). Thus, the removal of phospholipase $\mathrm{A}_{2}$ and other high molecular weight proteins could improve the product safety and allow the treatment of many diseases at low risk. The molecular weight cut off reported in the literature is usually $10,000 \mathrm{Da}$.

Purification of bee venom has been described by means of gel filtration, ion exchange chromatography and centrifugation. However, the production of a large scale purified fraction below $10 \mathrm{kDa}$ is not feasible by means of these methods. Recently, the use of ultrafiltration, a membrane process, for purification of bee venom was patented, with feed concentration ranging from 0.67 to $1 \mathrm{~g}$ apitoxin/L (Shen et al., 2014). The main advantage of ultrafiltration is the use of mild conditions and its modular character, a strategic choice for scaling up (Li and Chase, 2010).

The study of membrane transport properties with varying operating conditions can be an important tool to

\footnotetext{
*Corresponding author: Kátia Cecília de Souza Figueiredo. E-mail: katia@deq.ufmg.br; Phone: +55(31) 3409 1781; Fax: +55(31)3409 1789.
} 
prevent flux decrease and non-programmed interruptions in the process. Our goal in this paper was the investigation of a commercial ultrafiltration $10 \mathrm{kDa}$ membrane to perform apitoxin fractionation. The effects of feed content, pressure difference and stirring rate were addressed to characterize permeate flux and selectivity.

\section{MATERIALS AND METHODS}

\section{Materials}

Bee venom was purchased from Cooperativa Nacional de Apicultura, CONAP, Brazil. Regenerated cellulose ultrafiltration membranes with molecular weight cut off (MWCO) of $10 \mathrm{kDa}$ were purchased from Millipore. Analytical standards of melittin and phospholipase $\mathrm{A}_{2}$ were supplied by Sigma-Aldrich. Ultrapure water from a Milli-Q water purification system, $0.055 \mu \mathrm{S} / \mathrm{cm}$, was used as solvent.

\section{Membrane characterization}

Pure water flux was determined to infer the average membrane pore size. Samples were previously washed with pure water for 2 hours, with solvent changes at time intervals of 30 minutes, in order to remove the glycerol protective layer. Milli-Q water was transferred to the stirring cell (Amicon, $4 \mathrm{~mL}$ capacity) in which the membrane was placed in the bottom, as schematically shown in Figure 1.

Feed pressure was varied from 50 to $400 \mathrm{kPa}$ using $\mathrm{N}_{2}$. Permeate was collected in a proper recipient and membrane flux was calculated according to Equation 1:

$$
J=\frac{w}{A \Delta t}
$$

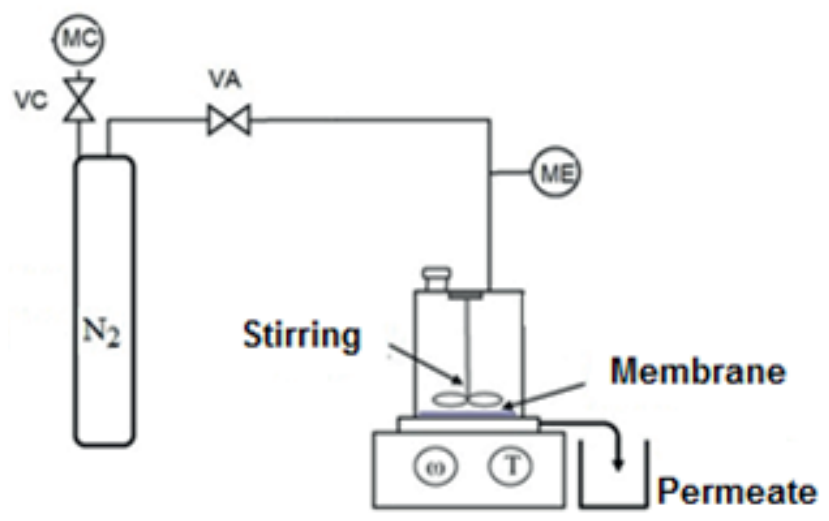

Figure 1. Schematic representation of ultrafiltration apparatus.VC and VA are the valves of cylinder and feed, $\mathrm{ME}$ and $\mathrm{MC}$ are the manometers of the system and cylinder, $\mathrm{w}$ and $\mathrm{T}$ are the stirring rate and temperature setups.
In Equation 1, $\mathrm{J}$ is the water flux, in $\mathrm{kg} / \mathrm{m}^{2} . \mathrm{h}, \mathrm{w}$ is the permeate weight, in $\mathrm{kg}, \mathrm{A}$ is membrane area, equal to $0.0013 \mathrm{~m}^{2}$, and $\Delta \mathrm{t}$ is the time of the experiment, in hours. Membrane hydraulic permeability, $\mathrm{L}_{\mathrm{p}}$ was determined by the slope of the flux versus pressure difference, $\Delta \mathrm{P}$, plot. Tests were performed in triplicate, at $25^{\circ} \mathrm{C}$ and stirring rate of $750 \mathrm{rpm}$.

\section{Membrane transport properties}

The effects of pressure difference (50 to $400 \mathrm{kPa}$ ), feed content ( 1 to $50 \mathrm{~g}$ apitoxin/L), stirring rate (180 to $960 \mathrm{rpm}$ ) and time (up to $400 \mathrm{~min}$ ) on membrane flux and rejection were investigated. The feed solution was prepared by dissolving apitoxin in Milli-Q water in the desired concentration. The resulting suspension was shaken in a vortex stirring tube for 5 minutes and microfiltrated in a $0.45 \mu \mathrm{m}$ pore diameter cellulose acetate membrane (Millipore). Permeate of microfiltration was fed to the Amicon stirred cell, in the same apparatus shown in Figure 1 , which was hermetically closed. The pressure difference across the membrane was adjusted by using $\mathrm{N}_{2}$ on the feed tank and permeate was kept in atmospheric pressure ( $1 \mathrm{~atm})$. The stirring rate was adjusted and the experiment was started. Permeate was transferred to a vessel and the weight was measured as a function of time. Tests were conducted in triplicate and the results were analyzed statistically.

The quantification of melittin and phospholipase $\mathrm{A}_{2}$ both in feed and permeate was determined using a High Performance Liquid Chromatograph, HPLC, equipped with a C18 column. The method was described elsewhere (Haghi et al., 2013).

Membrane flux was calculated according to Equation 1. Membrane rejection to phospholipase $\mathrm{A}_{2}$ was calculated according to Equation 2.

$$
R=1-\frac{C_{p}}{C_{f}}
$$

In Equation 2, $\mathrm{R}$ is membrane rejection, $\mathrm{c}_{\mathrm{f}}$ and $\mathrm{c}_{\mathrm{p}}$ are phospholipase $\mathrm{A}_{2}$ concentration in feed and permeate, respectively. Recovery of melittin was calculated by the mass ratio of the peptide in permeate and feed, respectively, multiplied by 100 .

\section{Permeate characterization}

Phospholipase $\mathrm{A}_{2}$ catalytic activity was investigated by using the egg yolk test. The egg yolk was homogenized in $100 \mathrm{~mL}$ of $0.9 \% \mathrm{NaCl}$ aqueous solution, by weight (solution I). This stock solution was 10-fold diluted in $0.9 \% \mathrm{NaCl}$ aqueous solution (solution II). After that, $1 \mathrm{~mL}$ of the solution II and $4.9 \mathrm{~mL}$ of $0.9 \% \mathrm{NaCl}$ aqueous solution were added in a test tube. This was placed in a 
water bath, at $41^{\circ} \mathrm{C}$, for 5 minutes. The absorbance was determined in a UV-visible spectrophotometer (Pharmacia LKB-Ultrospec III) at $900 \mathrm{~nm}$. Then, $0.1 \mathrm{~mL}$ of sample was added at a concentration of $1 \mathrm{~g} / \mathrm{L}$ in $\mathrm{PBS}, \mathrm{pH} 7.0,0.01 \%$ in weight. Absorbance at $900 \mathrm{~nm}$ was measured from 0 to 15 minutes, in time intervals of 5 minutes.

\section{RESULTS AND DISCUSSION}

\section{Membrane hydraulic permeability}

The results of pure water flux as a function of pressure difference through the membrane showed a linear behavior of flux with pressure difference, as expected. Membrane hydraulic permeability was $(0.43 \pm 0.04) \mathrm{kg} \cdot \mathrm{h}^{-1} \cdot \mathrm{m}^{-2} \cdot \mathrm{kPa}^{-1}$, lower than the value informed by the manufacturer, $0.61 \mathrm{~kg} \cdot \mathrm{h}^{-1} \cdot \mathrm{m}^{-2} \cdot \mathrm{kPa}^{-1}$. The deviation could be ascribed to large variation in membrane morphology, shown by scanning electron microscopy in Figure 2, and nitrogen physisorption, shown in Figure 3, which revealed pore diameters in the range of 3.7 to $125 \mathrm{~nm}$.

\section{Apitoxin ultrafiltration}

The results of pressure difference, apitoxin feed concentration and stirring rate on membrane flux for apitoxin aqueous solutions are presented in Figures 4, 5 and 6 . Fluxes were measured in the stabilized period.

The increase in flux with $\Delta \mathrm{P}$ (Figure 4) was expected because it is the driving force for the permeation. The point at which the flux did not increase with $\Delta \mathrm{P}$ is known as the critical flux, in which the concentration polarization of the system is significant. The phenomena can be explained in terms of the diffusive flow of the retained solutes from membrane surface back to bulk feed, decreasing permeate flux. The higher the apitoxin concentration in the feed, the lower was the critical flux, in accordance with the concentration polarization theory: an increase in solute content causes polarization and flux stabilization at lower pressure differences. Further tests were conducted at a pressure difference of $70 \%$ of the one corresponding to the critical flux, to prevent concentration polarization.

The effect of concentration polarization was confirmed in Figure 5 . A decrease of $51 \%$ in permeate flux was obtained with the increase in content from 5 to $50 \mathrm{~g}$ apitoxin/L. This could be explained by the dead-end mode of experimental setup, which implies a huge increase in protein concentration during the test, due to the reduction in feed volume, and also a high concentration polarization with time.

The increase in stirring rate caused an increase in permeate flux, Figure 6, as the result of the reduction in concentration polarization layer thickness, since the hydrodynamic conditions are improved, favoring the transport. The increase in stirring rate from 80 to $960 \mathrm{rpm}$ caused an increase in permeate flux higher than $140 \%$. However, stirring rates higher than $750 \mathrm{rpm}$ led to a very thick layer of foam in the feed tank, which is probably due to the amphipathic character of apitoxin substances, such as melittin and phospholipase. This foam layer is undesired in such process since it could decrease membrane yield, as proteins would be displaced from the feed/membrane interface to form a huge volume structure in the feed tank.

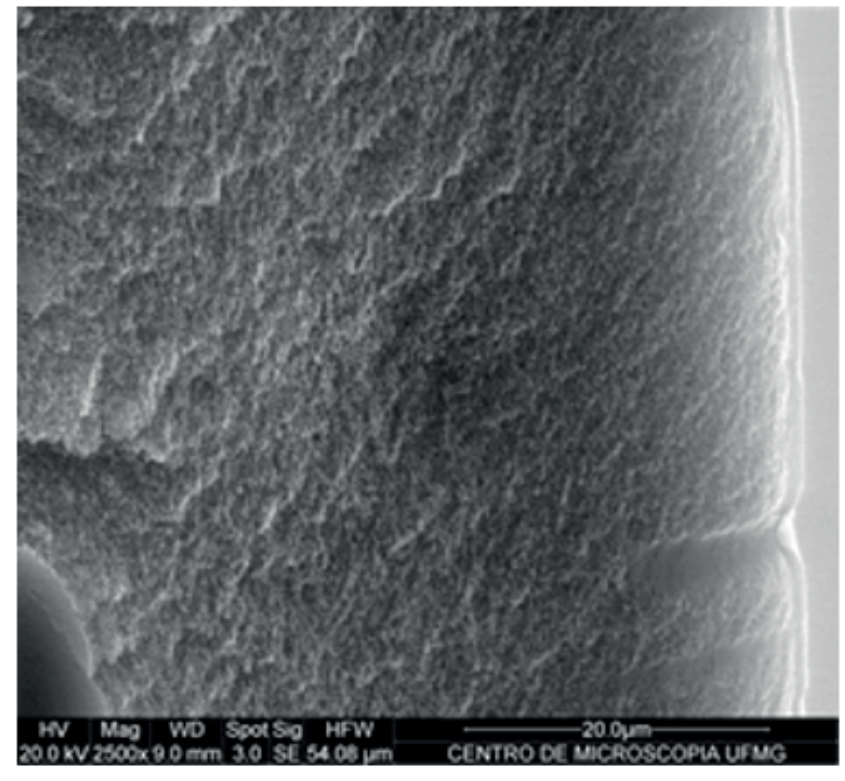

(a)

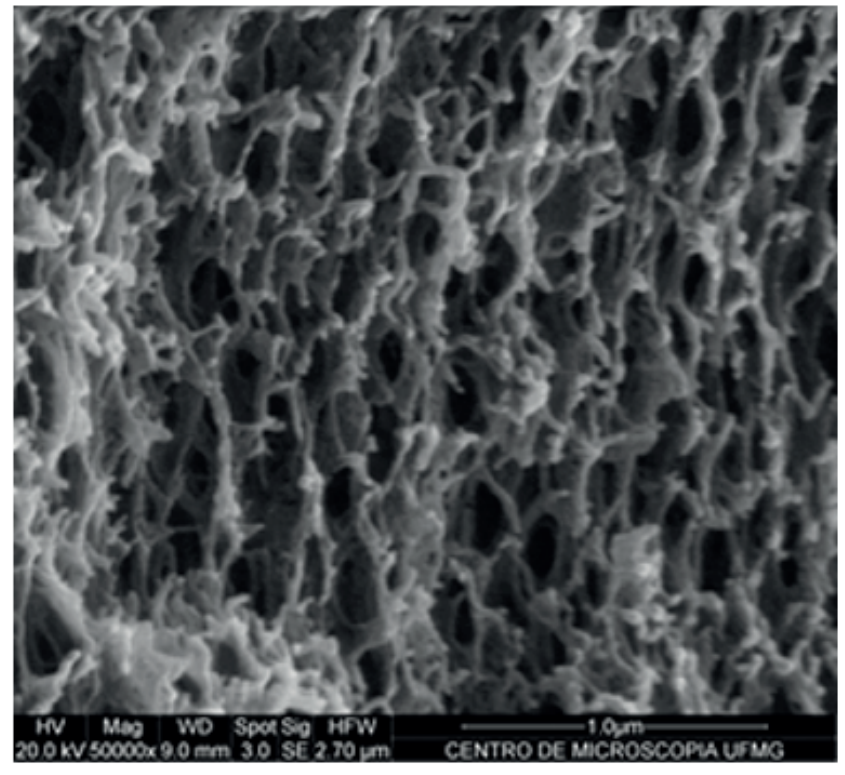

(b)

Figure 2. SEM images of the membrane cross section. (a) Membrane skin (right) and sublayer (left), (b) zoom in sublayer porous structure. 


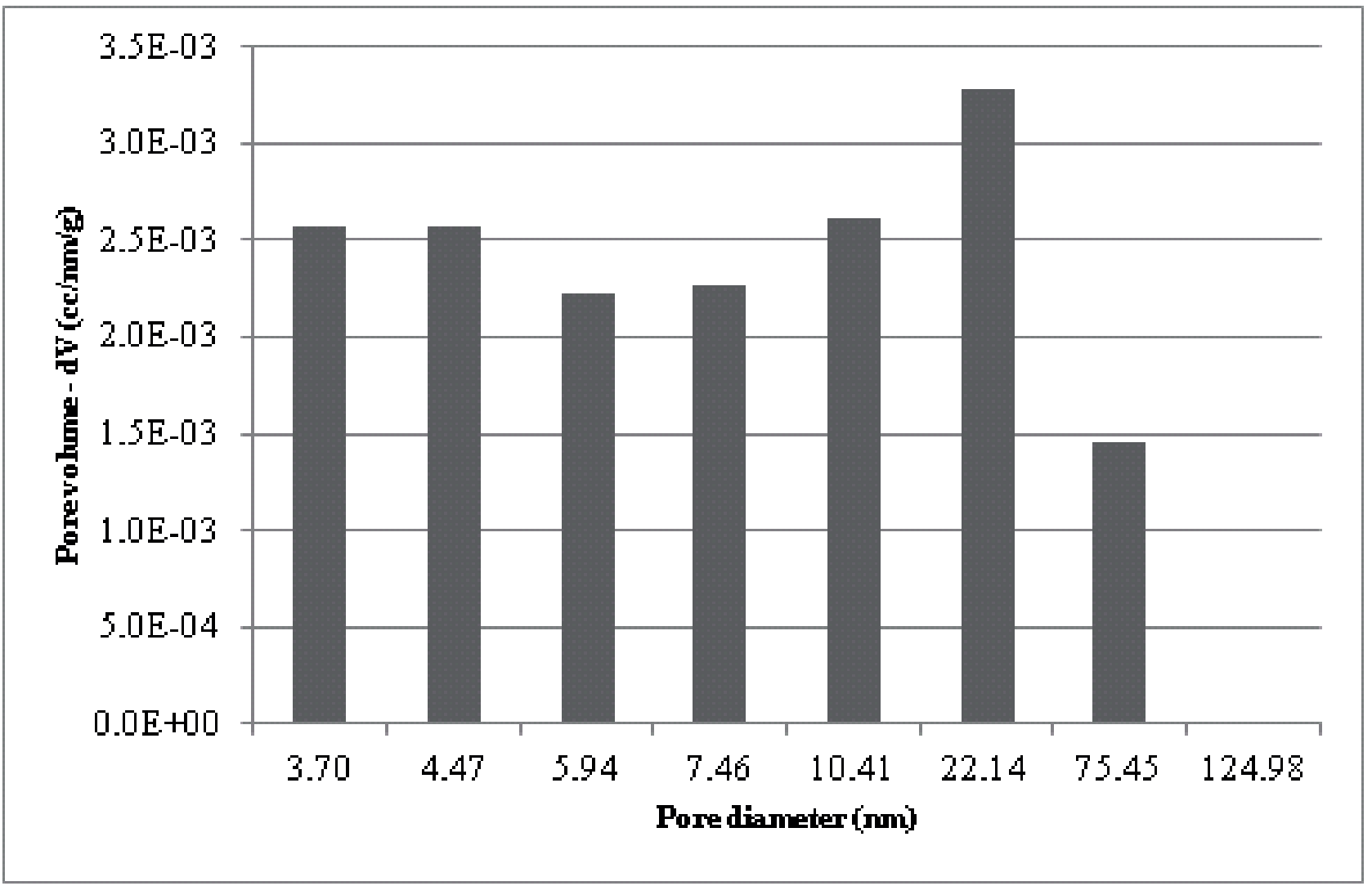

Figure 3. - Pore size distribution of cellulose acetate ultrafiltration membrane determined by nitrogen physisorption.

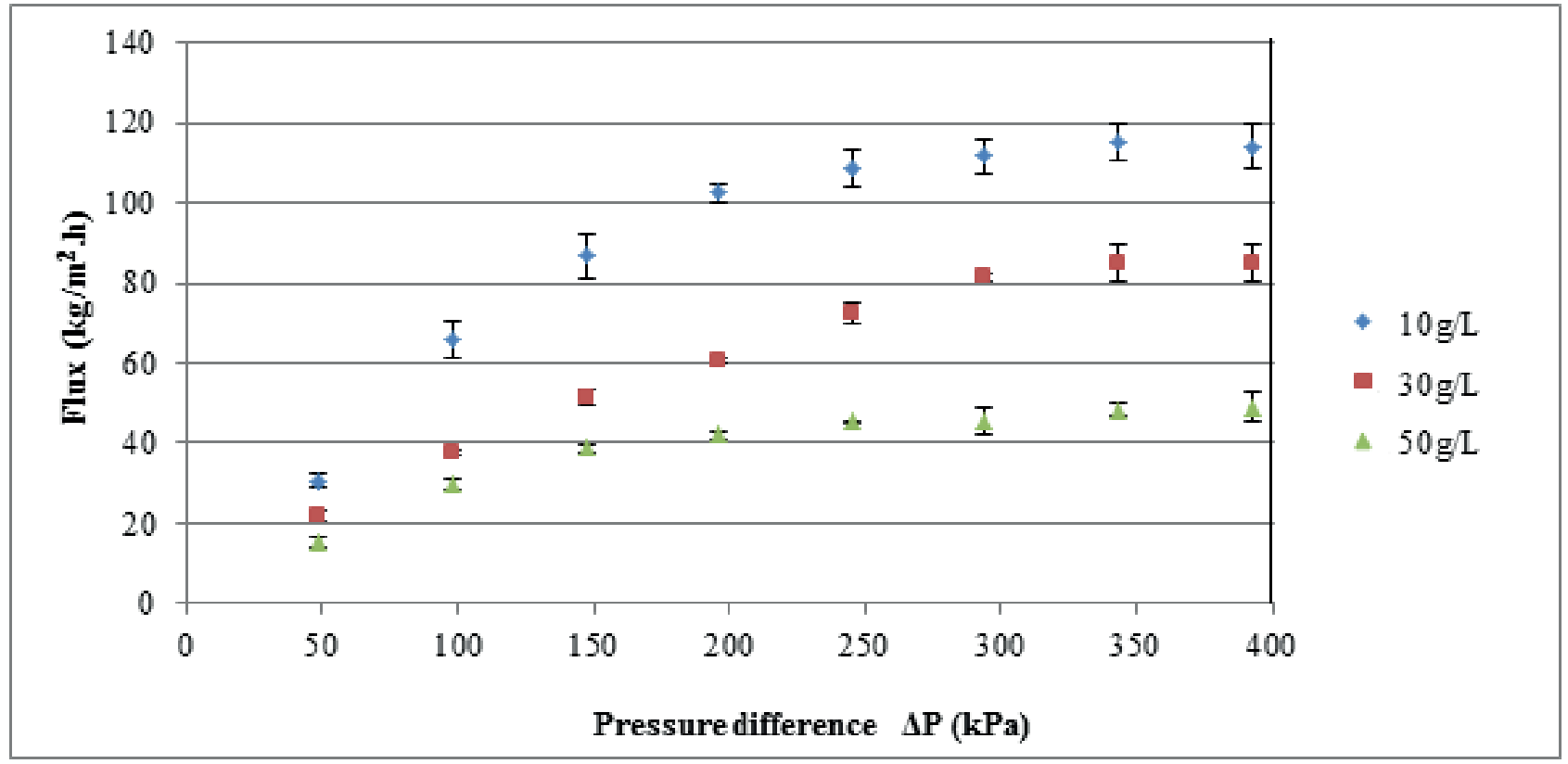

Figure 4. Effect of pressure difference on membrane flux after stabilization for different apitoxin feed contents. Temperature $=25^{\circ} \mathrm{C}, \mathrm{Membrane}$ area $=0.0013 \mathrm{~m}^{2}$, stirring rate $=750 \mathrm{rpm}$. 


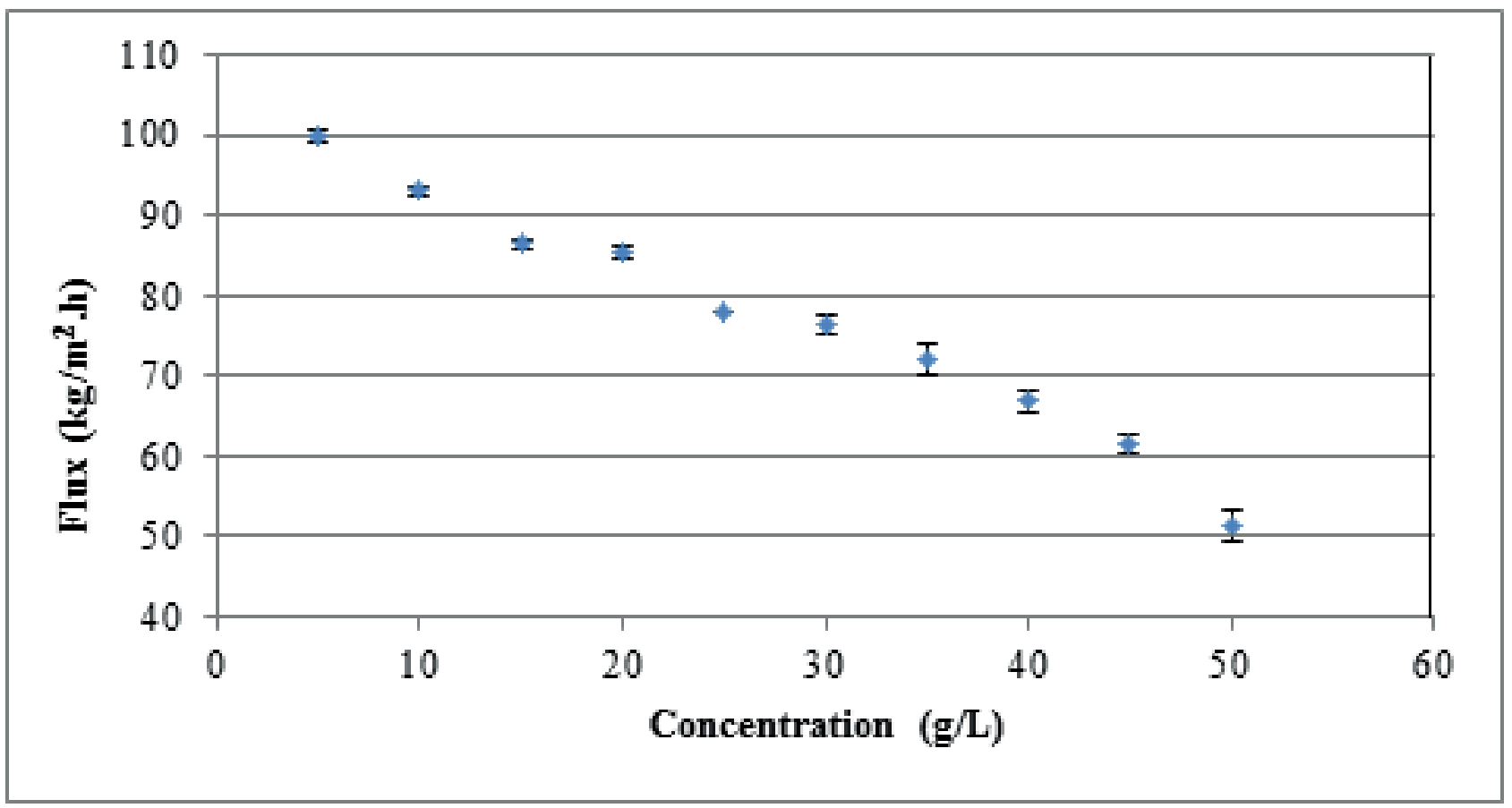

Figure 5. Effect of apitoxin concentration on membrane flux after stabilization. Temperature $=25^{\circ} \mathrm{C}$, Membrane area $=0.0013 \mathrm{~m}^{2}$, stirring rate $=750 \mathrm{rpm}, \mathrm{DP}=220 \mathrm{kPa}$.

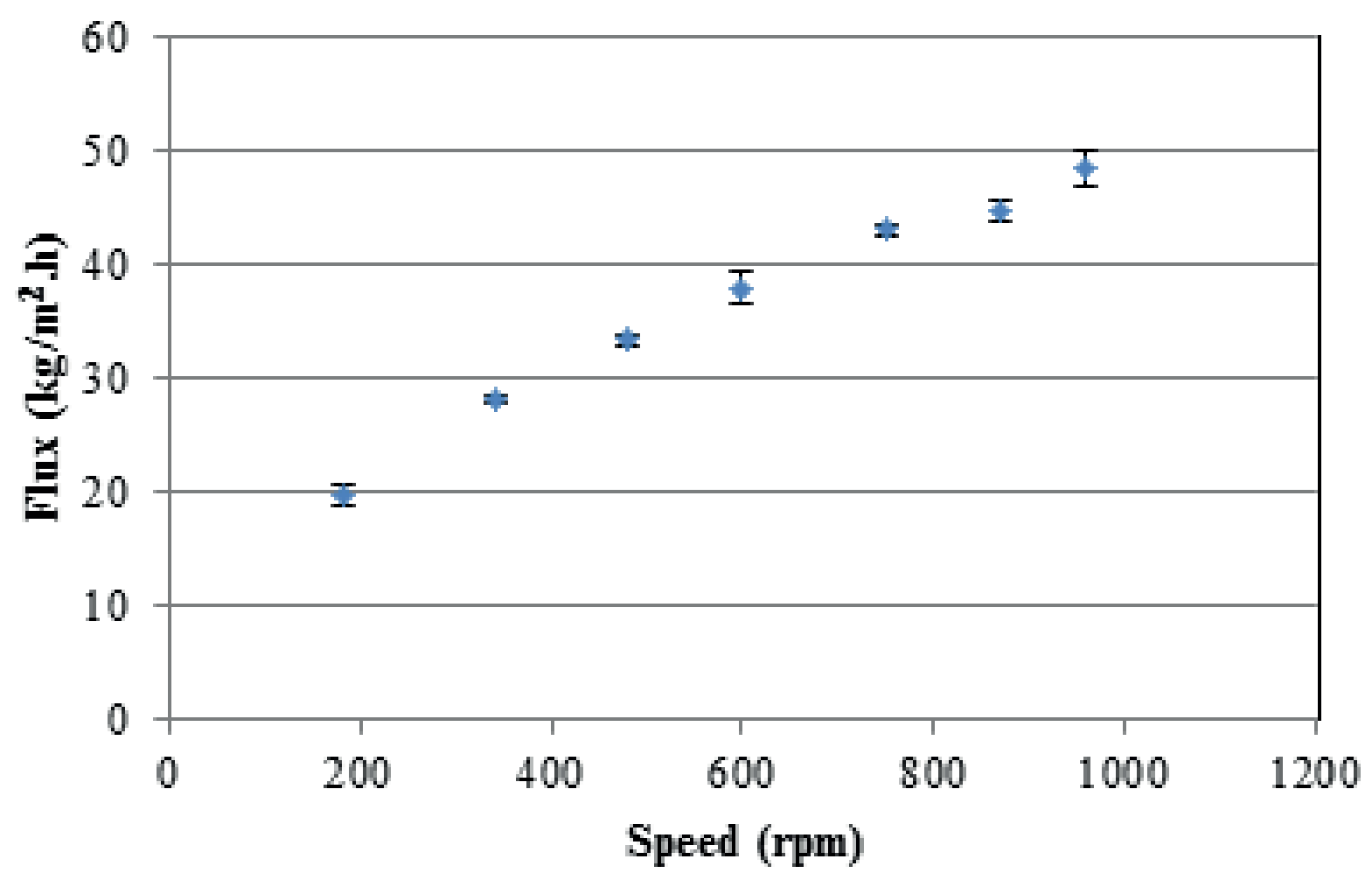

Figure 6. Effect of stirring rate on membrane flux after stabilization. Temperature $=25^{\circ} \mathrm{C}$, Membrane area $=0.0013 \mathrm{~m}^{2}$, apitoxin feed content $=30 \mathrm{~g} / \mathrm{L}, \mathrm{DP}=220 \mathrm{kPa}$. 
The use of tangential flow over membrane surface instead of dead-end mode could increase process yield, since the hydrodynamic conditions would be improved. However, our main goal in this work was the investigation of $10 \mathrm{kDa}$ membrane with high apitoxin feed content.

Figure 7 shows a significant decrease in membrane hydraulic permeability after immersion in feed solution (30 $\mathrm{g}$ apitoxin/L) for 24 hours, especially with the increase in $\Delta \mathrm{P}$. No cleaning procedure was conducted. This is typical of a polarized system, in which water permeation was disfavored, indicating that some of the apitoxin components could be adsorbed in membrane pores and could not be washed out by pure water.

Tests with the same membrane over 400 minutes, Figure 8, showed an initial decrease in membrane flux, but it stabilized at 300 minutes, which characterizes concentration polarization phenomena, with no fouling. A fouled membrane would have caused a marked flux decrease with time without a stabilization step.

The isoelectric point of the majority of peptides in apitoxin is basic. In $\mathrm{pH}$ 6.5-7.0, the condition of the tests, a high interaction was not expected between peptide/peptide and peptide/membrane. Being positively charged, most peptides will repeal each other, while the hydrophilicity of the cellulose membrane would not characterize an ionic interaction. This could explain the absence of fouling during the tests, since membrane flux was stabilized after a few minutes, even for the highest apitoxin feed content (Wang and Tang, 2011).

Regarding selectivity, a feed content of $30 \mathrm{~g}$ apitoxin/L revealed that only $7 \%$ of melittin permeated the membrane, while phospholipase $\mathrm{A}_{2}$ showed $40 \%$ of rejection. One possible explanation for the low recovery of melittin is the formation of a tetramer in aqueous solution, leading to a larger molecule, rejected by membrane pores. The high concentration of melittin in feed can favor the aggregation kinetics (Qiu et al., 2005). On the other hand, it is worth noting that $10 \mathrm{kDa}$ is the nominal cut off of the membranes, which can show a broad range of membrane pore size (from 3.7 to $125 \mathrm{~nm}$ ). This can justify the permeation of both melittin tetramer and phospholipase $\mathrm{A}_{2}$.

Alternatively, a feed content of $1 \mathrm{~g}$ apitoxin/L was investigated. Membrane flux was $103 \mathrm{~kg} / \mathrm{m}^{2} \mathrm{~h}$, while melittin recovery was $58.6 \%$ and the rejection of phospholipase $\mathrm{A}_{2}$ was $59.9 \%$, respectively. Thus, the decrease in apitoxin content in the feed can improve significantly the membrane transport properties.

The mass transfer coefficient was determined by considering the range of feed concentration of apitoxin. This is an important parameter in order to scale up the separation unit. The gel layer model was used to

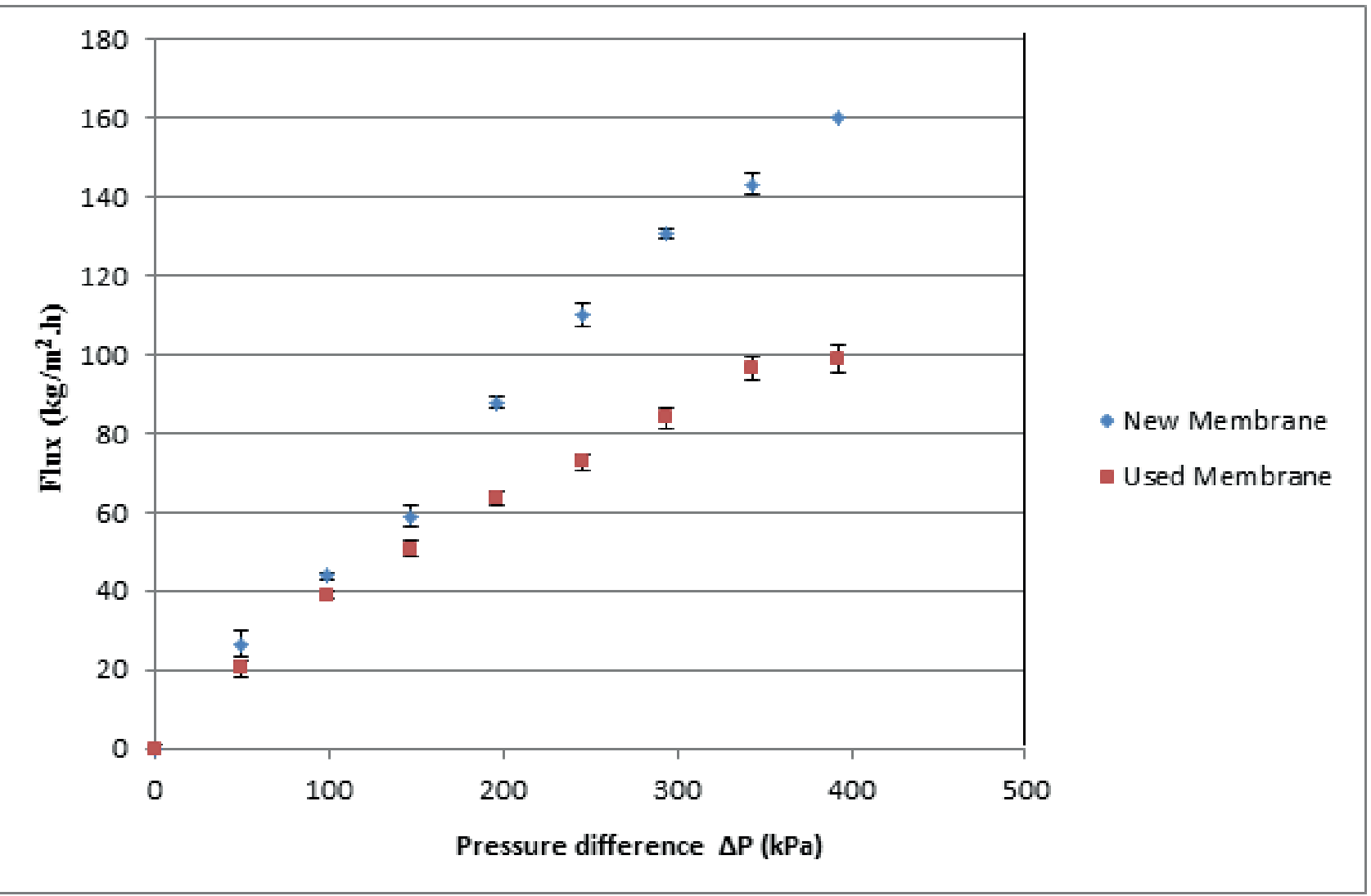

Figure 7. Evolution of membrane water initial flux as a function of pressure difference before and after immersion in apitoxin solution. Temperature $=25^{\circ} \mathrm{C}$, Membrane area $=0.0013 \mathrm{~m}^{2}$, stirring rate $=750 \mathrm{rpm}$. 


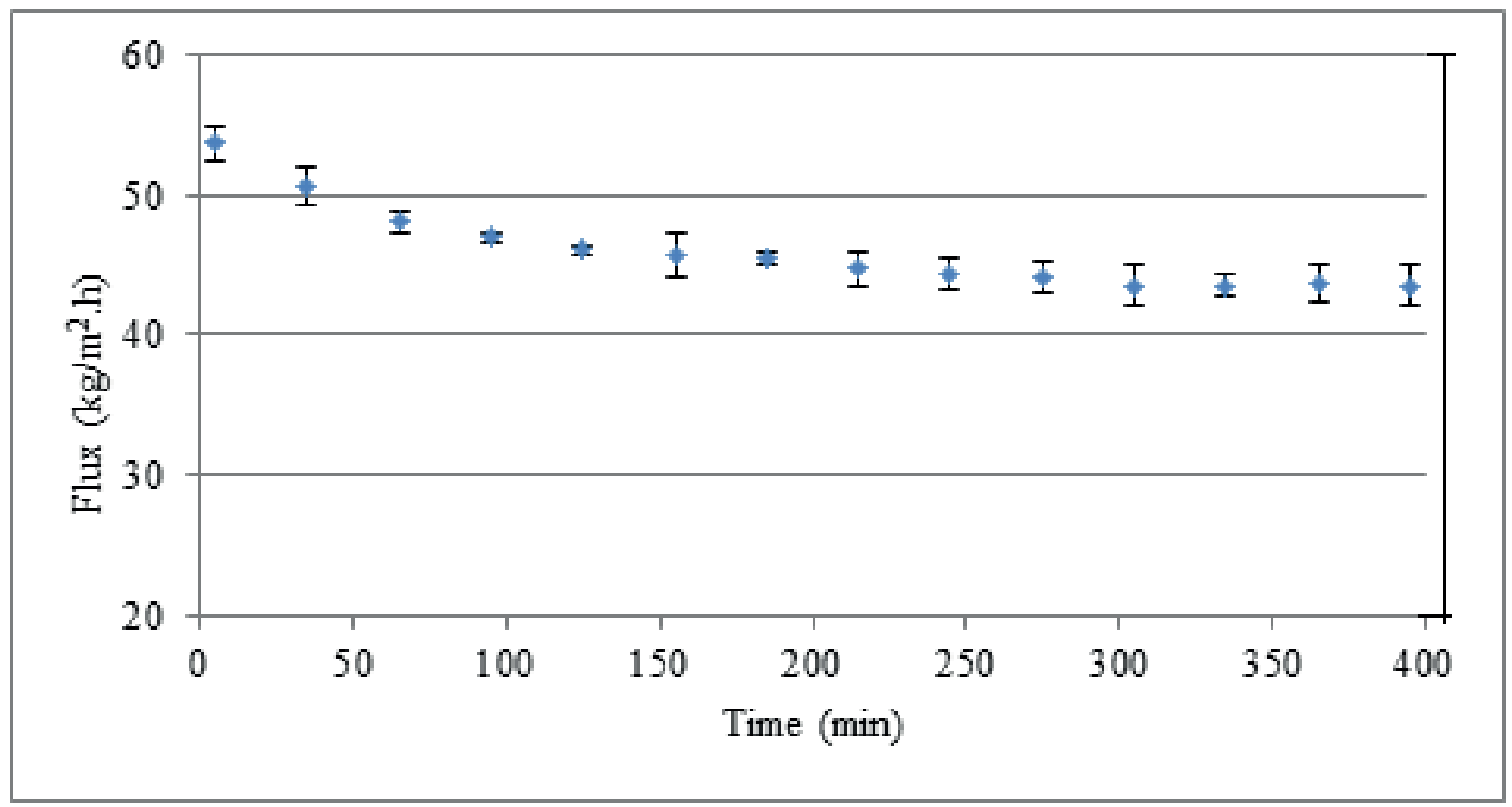

Figure 8. Variation of flux with time for the ultrafiltration of apitoxin solution. Temperature $=25^{\circ} \mathrm{C}$, Membrane area $=0.0013 \mathrm{~m}^{2}$, stirring rate $=750 \mathrm{rpm}$, apitoxin feed concentration $=30 \mathrm{~g} / \mathrm{L}$ and $\Delta \mathrm{P}=220 \mathrm{kPa}$.

estimate this parameter, in which the flux was plotted against total protein concentration (Baker, 2004), the extrapolation of the straight lines to zero flux is regarded as $\mathrm{C}_{\text {gel, }}$ the concentration of gel layer deposited over the membrane. Upon considering that the values of flux, diffusion coefficient, and polarized thickness are constant, one may determine the resistance of this layer to the transport, since the membrane resistance was neglected. Equation 3 was used to calculate the mass transfer coefficient, $\mathrm{k}$.

$$
J_{i}=k\left(c_{i b}-c_{g e l}\right)
$$

where $\mathrm{C}_{\mathrm{ib}}$ is the apitoxin feed content.

The mass transfer coefficient was $5.28 \times 10^{-6}$ $\mathrm{m} / \mathrm{s}$, which could be improved by means of changing the stream profile inside the module. For instance, as mentioned before, the use of a tangential flow of feed could decrease concentration polarization of the system.

Upon considering the permeate, the phospholipase $\mathrm{A}_{2}$ content was reduced from 12 to $4.8 \%$ in weight, which is significant to improve product safety. However, the choice of another membrane with less broad pore size distribution would be interesting for further tests.

\section{Phospholipase activity}

The results of the egg yolk test are presented in Figure 9. The low decrease in absorbance for the permeate indicated that phospholipase $\mathrm{A}_{2}$ did not show the ability to catalyze the hydrolysis of phospholipids. This might be explained due to the denaturation of the enzyme during permeation tests through the membrane, possibly as the result of the interfacial interaction of the macromolecule with the solid irregular pores (Thomas and Geer, 2011). This result is significant, since the permeate can improve product safety.

\section{CONCLUSION}

Ultrafiltration in a $10 \mathrm{kD}$ cellulose membrane can perform the fractionation of apitoxin to develop a preparation for the treatment of rheumatoid arthritis. The results were very dependent on apitoxin feed content, which influenced both membrane flux and rejection. Melittin showed a low recovery from the feed solution (30 $\mathrm{g}$ apitoxin/L), probably due to agglomeration of peptides. On the other hand, the best result was observed for $1 \mathrm{~g}$ apitoxin/L, with a flux of $103 \mathrm{~kg} / \mathrm{m}^{2} \mathrm{~h}$, phospholipase $\mathrm{A}_{2}$ rejection of $60 \%$ and melittin recovery of $59 \%$. The reduction in phospholipase $A_{2}$ catalytic activity, the most allergenic substance of apitoxin, is a compelling result to further investigate the system aiming at large scale production.

\section{ACKNOWLEDGEMENTS}

Authors thank the Fundação de Amparo à Pesquisa do Estado de Minas Gerais (FAPEMIG) for financial support. 


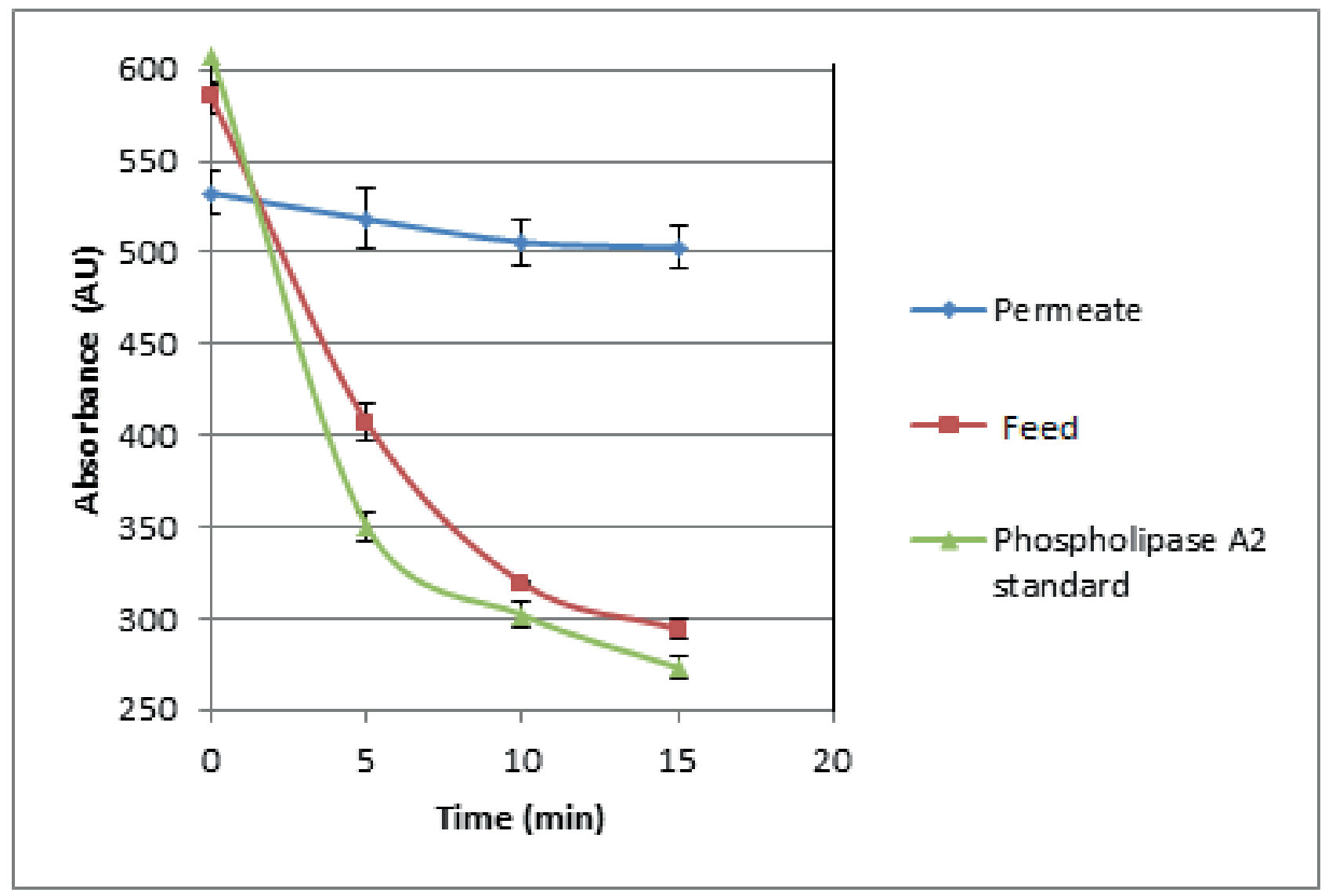

Figure 9. Egg yolk test for phospholipase $\mathrm{A}_{2}$ in permeate, feed (apitoxin solution) and standard (control).

\section{REFERENCES}

Baker, R. W., Membrane Technology and Applications.2 ${ }^{\text {nd }}$ Ed., Menlo Park, John Wiley \& Sons, 2004.

Dong, J. S., Jae, W. L., Young, H. L., Ho, S. S., Chong, K. L. and Jim, T. H., Therapeutic application of anti-arthritis, pain-releasing, and anti-cancer effects of bee venom and its constituent compounds, Pharmacology \& Therapeutics, 115, No. 2, 246 (2007).

Haghi, G., Hatami, A. and Mehran, M., Qualitative and quantitative evaluation of melittin in honeybee venom and drug products containing honeybee venom, Journal of Apicultural Science, 57, No. 2, 37 (2013).

Li, J. and Chase, H.A., Applications of membrane techniques for purification of natural products, Biotechnology Letters,32, No. 5, 601 (2010).

Merlo, A. L., Bastos, L. F. S., Godin, A. M., Rocha, L. T. S., Nascimento Junior, E. B., Paiva, A. L. L., Moraes-Santos, T., Zumpano, A. A. C., Bastos, E. M. A. F., Heneine, L. G. D. and Coelho, M. M., Effects induced by Apis mellifera venom and its components in experimental models of nociceptive and inflammatory pain, Toxicon, 57, No. 5, 764 (2011).
Müller, U., Schmid-Grendelmeier, P., Hausmann, O. and Helbling, A., IgE to recombinant allergens api $\mathrm{m} 1$, Ves v1 and Ves v 5 distinguish double sensitization from crossreaction in venom allergy, Allergy, 67, No. 8, 1069 (2012).

Qiu, W., Zhang, L., Kao, Y.T., Lu, W., Li, T., Kim, J., Sollemberger, G.M., Wang, L., Zhong, D., Ultrafast hydration dynamics in melittin folding and aggregation: helix formation and tetramer self-assembly. The Journal of Physical Chemistry B, 109, No. 35, 16901 (2005).

Shen, C.Z., Won, H.Y., Kim, S.J., Lee, J.Y., Shin, Y.H., Lee, S.Y., Park, J.K., Kim, E.K. and Kim, C.G., Preparation method for isolated, purified bee venom having allergic components isolated, International patent WO 2014196674 A1(2014).

Thomas, C.R. and Geer, D., Effects of shear on proteins in solution, Biotechnology Letters, 33, No. 3, 443 (2011).

Wang, N.Y. and Tang, C.Y., Protein fouling of nanofiltration, reverse osmosis and ultrafiltration membranes - the role of hydrodynamic conditions, solution chemistry and membrane properties, Journal of Membrane Science, 376, No. 1-2, 275 (2011). 